\title{
DETERMINATION OF PEARLITE MORPHOLOGY IN HIGH-CARBON HOT ROLLED STEEL
}

The article presents the results of tests of influence of the thermo-mechanical treatment parameters on the mechanical properties and microstructure of steel C70D for wire rod. The methodology of quantitative description of pearlite morphology in steels with the use of the method on which a new computer program "PILS" - Pearlite Inter-Lamellar Spacing is based was presented. In order to verify the method, some quantitative tests of microstructure in samples after physical simulation of heat-plastic treatment were conducted on a deformation dilatometer device with diverse cooling rate for steel C70D. The process of rolling was conducted in simulation in continuous finishing train arrangement. Elaborated program and conducted tests will be used during preparations of modified technologies of wire rod rolling to prepare products made of steel, the microstructure of which is characterised with smaller interlamellar spacing.

Keywords: microstructure, quantitative metallography, interlamellar spacing, physical simulation

\section{Introduction}

High-carbon steel types for wire rod are rolled in modern continuous systems $[1,2]$. Linear velocity of rolling wire rod in such systems equals up to $120 \mathrm{~m} / \mathrm{s}$. In such dynamic conditions the parameters of rolling process and later cooling process play an important role in shaping the microstructure and mechanical properties. Constant growth in requirements concerning properties of the products needs improvement of manufacturing technology. Conduction of experiments in order to choose the optimal parameters of the process on industrial production lines is very difficult due to the need of application of a big amount of material in a singular process. That is why laboratory rolling mills are constructed to illustrate the conditions of the real rolling process in a more detailed way [3]. At present the temperature of rolling finish for high-carbon steel types is $900-920^{\circ} \mathrm{C}$. In practice the achievement of the assumed structure of wire rod from high-carbon steel is possible in Stelmor production line with the use of fans of the first cooling sections working with high efficiency. It enables fast cooling of the band to a temperature of the beginning of pearlitic transition. The amount of mechanical properties in pearlitic steel types depends on the degree to which pearlite is dispersed. The main stereological parameter applied to describe this dispersion is the so-called real interlamellar spacing $\lambda_{0}$ defined as the distance between two midpoints of two subsequent lamellae of cementite or ferrite in a given colony of pearlite. There are methods of direct measurement for this value [4-6]. However, they are time-consuming and need a lot of effort. The measurement can be conducted manually but a better solution would be the automation of the process [7]. The article presents the methodology of automatic quantitative description of pearlite morphology in steels with the use of the method on which a new computer program. Within the verification process there were quantitative tests performed of microstructures of samples after physical simulation of heat-plastic treatment on deformation dilatometer with varied cooling rate and using rolling in continuous finishing train arrangement. Achieved results will be used to improve the process of rolling on industrial production lines.

\section{Methodology of quantitative measurements of pearlite in PILS program}

The main stereological parameter applied to describe this dispersion is the so-called real interlamellar spacing $\lambda_{0}$ defined as the distance between two midpoints of two subsequent lamellae of cementite or ferrite in a given colony of pearlite. Due to that fact the real interlamellar spacing is usually calculated on the basis of the measurements of the distance between such two lamellae and conducted on metallographic microsections. The most commonly measured values are the so-called apparent spacing $\lambda_{a}$ and random spacing $\lambda_{r}$.

The measurement can be conducted manually but a better solution would be the automation of the process. The result of the taken action is the original authors' program called PILS (from Pearlite Inter-Lamellar Spacing). Interlamellar spacing was determined on the basis of images registered on scanning

\footnotetext{
SILESIAN UNIVERSITY OF TECHNOLOGY, 8 KRASIŃSKIEGO STR., KATOWICE, POLAND

\# Corresponding author: dariusz.kuc@polsl.pl
} 
microscope Hitachi S4200. During the creation of the program two groups of problems needed to be solved. First was connected with the correct detection of cementite lamellae and the second was connected with the algorithm which would enable measurements of the apparent and random interlamellar spacing. It was assumed that the detection will be conducted automatically with minimum interference of the operator (if the need arises). Measurement of the random spacing would be conducted automatically on manually drawn measurement circles whereas the apparent spacing would be measured totally automatically. Second method mentioned provides more complex characteristics of interlamellar spacing. That is why more attention will be devoted to the second one. Parameters of binarisation and the processing of the achieved binary images were chosen in reference to the images of structure registered with the use of scanning microscope in technology of secondary electrons (SE). The output image was initially smoothed with the use of Gauss filter with $3 \times 3$ die and next subject to automatic binarisation with the use of k-means method [8]. After acceptation of the achieved binary image, all of the samples undergo the process of skeletonisation and the achieved skeletons are divided into segments. The skeleton of the object is built of its midpoints, which are points equally distant from the contour of the object. It can be noticed, on the basis of observations of real pearlitic structures that the apparent spacing between two lamellae measured in two different points does not have to be equal. That is why it is assumed in the PILS program that such spacing will be marked individually for each midpoint of a given lamella. The procedure used in order to achieve the aim consists of the following stages:

- Marking the equation of straight line perpendicular to the skeleton in the analysed midpoint. The bases of the calculation are coordinates of 10 points in skeleton situated in the closest distance from the point.

- Search of the points of intersection of this straight line with the skeletons of the neighbouring lamellae. This process begins in the analysed midpoint and is based on the movement on the marked straight lines in opposite directions until a pixel with the value of 1 is met or in case the distance from the analysed point gets bigger from the initially declared one. Distances of the found pixels from the given midpoint are included in the set of local interlamellar spacing of the analysed lamella.

- Set of local interlamellar spacing achieved for all midpoints of given lamella allows for calculation of minimum, maximum and mean interlamellar spacing and the variation indicator of such spacing.

This procedure is repeated for each cementite lamella which is detected on the image beginning from the one located in the highest point. The correctness of its functioning was assessed in the images created with the use of PILS program which works in verifying mode, specially prepared for such need. The example image of such type is presented in (Fig. 1).

Segments marked in blue and green connect the chosen midpoints of the subsequent lamellae with the points of the skeleton of the neighbouring lamellae. Their length corresponds

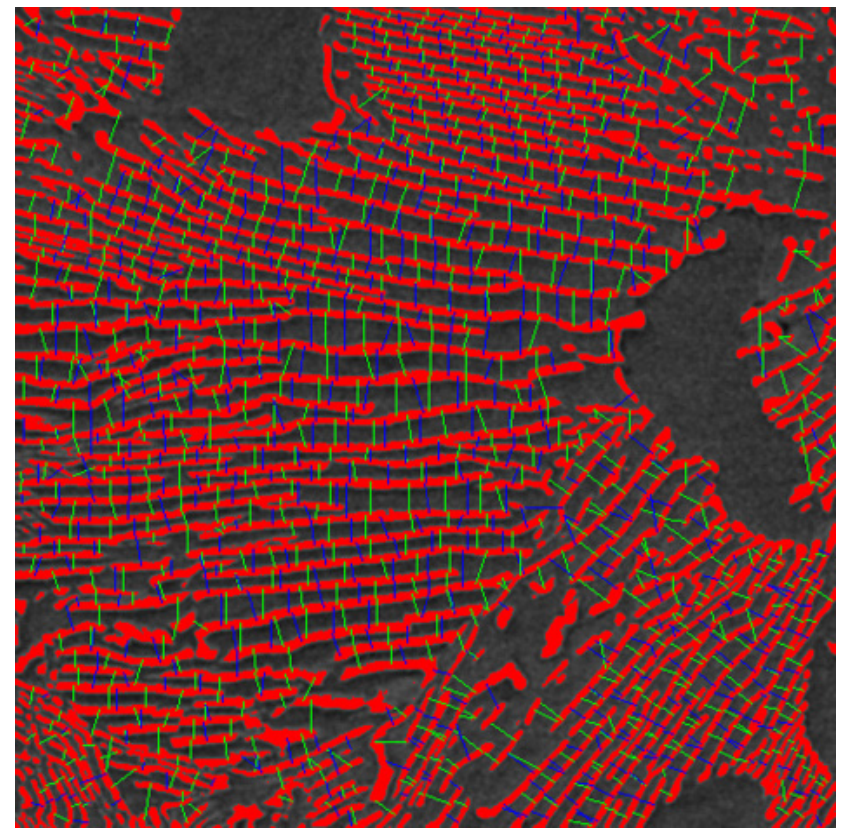

Fig. 1. Example view of pearlitic structure with section created with the use of PILS program, the length of which corresponds with the local interlamellar spacing

with the local apparent interlamellar spacing $\lambda_{r}$ Location and length of those segments created during verification on pearlitic structure images with varied morphology clearly prove that the procedure of marking the interlamellar spacing in accordance with the assumptions of the PILS program works correctly and the achieved results precisely characterise this feature of pearlite. Additionally, during the interlamellar spacing measurement the thickness of cementite lamellae is also being measured. The achieved results can be presented in various ways. Usually it is a table or a diagram. However, there is a possibility to paint the cementite lamellae with the use of different colours depending on the value of measured parameter achieved for given lamella. Examples of such presentation of results are shown in (Fig. 2).

\section{Materials and methodology of hot working}

Materials for tests were rods made of steel C70D meant for wire rods. The content of particular chemical elements is defined in the norm EN 10016-2: 1995. Physical simulation of heat-plastic treatment was determine on dilatometer. Samples we heated up to $900^{\circ} \mathrm{C}$, deformed with a strain $\varepsilon=0.3$ and cooling with varied rates from 0.1 to $10^{\circ} \mathrm{C} / \mathrm{s}$. There were no bigger cooling rate applied due to the appearing bainitic transformation. Rods from steel C70D were gathered after continuous casting rolling in breakdown passes in 17 cage block. Further rolling was conducted on semi-continuous laboratory mill for rolling bars in VSB - Technical University of Ostrava, Faculty of Metallurgy and Materials Engineering. Czech Republic [5]. Initial rolling of rods was conducted on 6 breakdown passes from diameter of $\varnothing 30 \mathrm{~mm}$ to $\varnothing 15.8 \mathrm{~mm}$ on a reversing rougher. Before rolling the rods were heated to a temperature of $1100^{\circ} \mathrm{C}$ and holding time for 


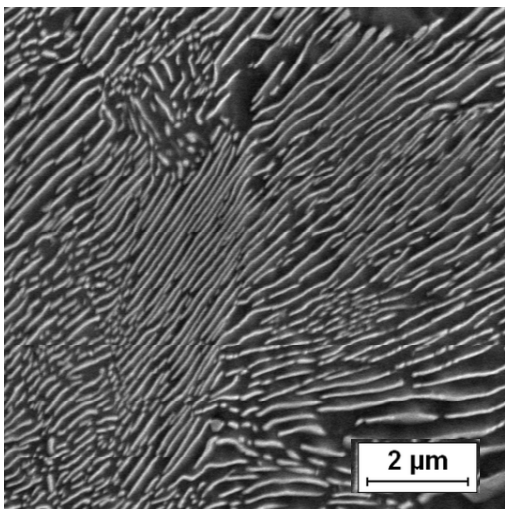

a)

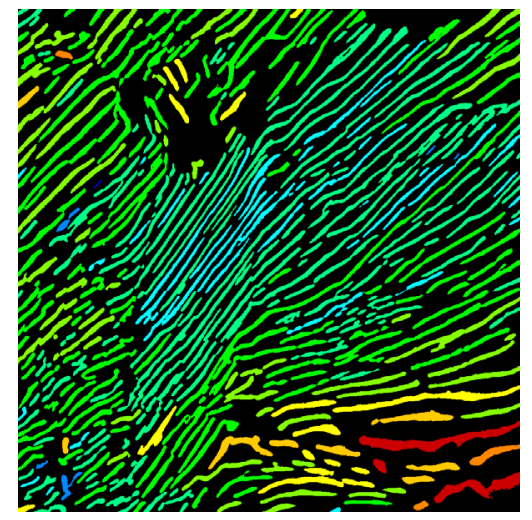

b)

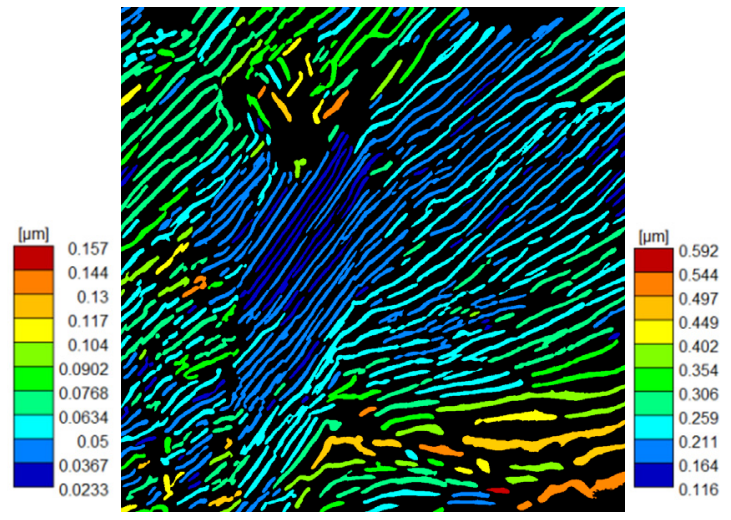

c)

Fig. 2. Microstructure of pearlite steel C70D registered on scanning microscope (a) and results of lamellae thickness measurements of cementite (b) and average spacing between them (c). Values of measured parameters for lamellae in the same colour are those which are situated in the same size class

30 minutes. Finish rolling was performed on four-rolling stands of continuous finishing mill from diameter of $\varnothing 15.6 \mathrm{~mm}$ to $\varnothing 9.8$ $\mathrm{mm}$. Finish rolling was conducted in three different temperature options: $750^{\circ} \mathrm{C}, 800^{\circ} \mathrm{C}, 850$ and $920^{\circ} \mathrm{C}$. After rolling rods were fast cooling using water shower (average cooling rate $7.5^{\circ} \mathrm{C} / \mathrm{s}$ ) to a temperature about $600^{\circ} \mathrm{C}$ and next with furnace with a rate of $0.4^{\circ} \mathrm{C} / \mathrm{s}$ to $400^{\circ} \mathrm{C}$ and next in air to a room temperature was applied.

\section{Results}

Registered microstructure of the example sample were presented on (Fig. 3). The aim of dilatometric tests was to determine the dependencies of interlamellar spacing $\left(\lambda_{a v}\right)$ from cooling rate after deformation $(v)$. Results are shown in (Table 1). In the analysed range of cooling rates the interlamellar distance decreases for high-carbon steel C70D from $0.425 \mu \mathrm{m}$ to 0.162

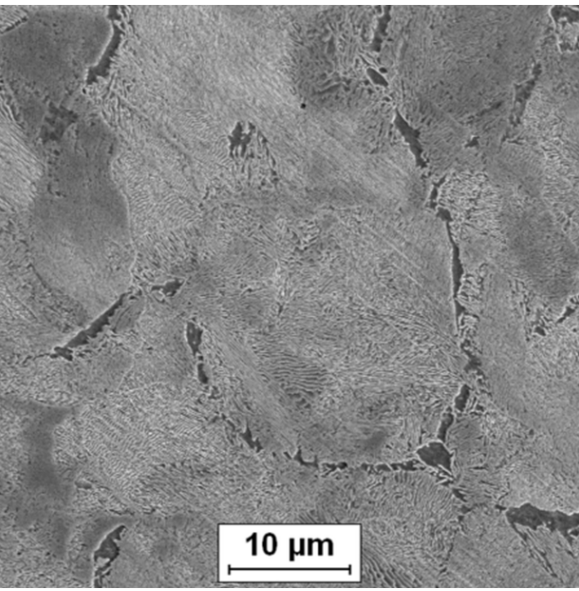

a)

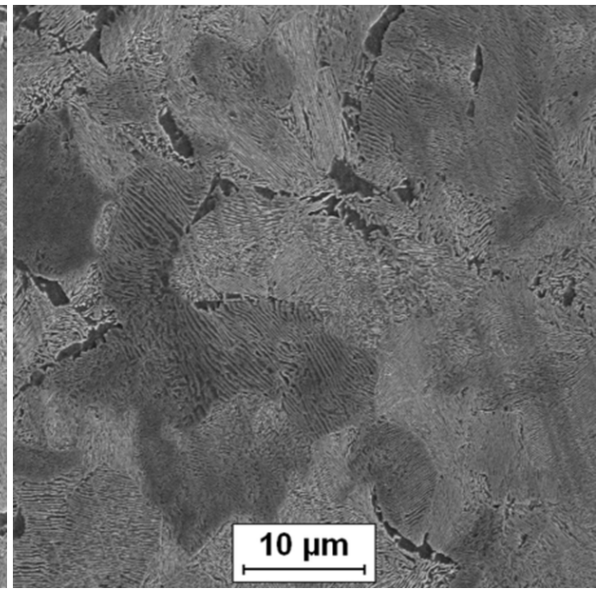

b)

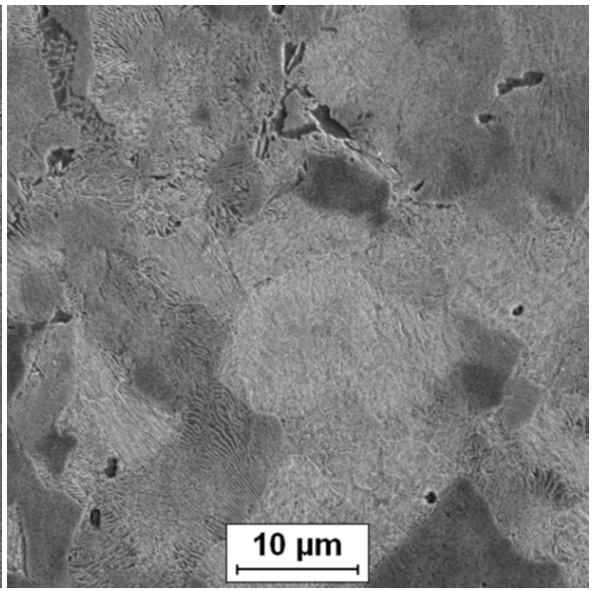

c)

Fig. 3. Microstructure of C70D steel after cooling with rate: $0.1,2.5$ and $7.5^{\circ} \mathrm{C} / \mathrm{s}$.

TABLE 1

Results of quantitative analysis of microstructure of pearlite lamellae in steel C70D - after simulation of heat-plastic treatment on deformation dilatometer device with diverse cooling rate

\begin{tabular}{|c|c|c|c|c|}
\hline \hline $\begin{array}{c}\text { Cooling rate after } \\
\text { deformation }(\boldsymbol{n}),\left[{ }^{\circ} \mathbf{C} / \mathbf{s}\right]\end{array}$ & $\begin{array}{c}\text { Average interlamellar } \\
\text { spacing } \lambda_{\boldsymbol{a v}}[\boldsymbol{\mu \mathrm { m } ]}\end{array}$ & $\begin{array}{c}\text { Minimum distance } \\
\lambda_{\min }[\boldsymbol{\mu m}]\end{array}$ & $\begin{array}{c}\text { Maximum distance } \\
\lambda_{\max }[\boldsymbol{\mu m}]\end{array}$ & $\begin{array}{c}\text { Variation index } \\
\boldsymbol{n}(\boldsymbol{\lambda})[\%]\end{array}$ \\
\hline 0.1 & 0.425 & 0.103 & 0.899 & 32.4 \\
\hline 1 & 0.242 & 0.093 & 0.643 & 34.0 \\
\hline 2.5 & 0.191 & 0.083 & 0.421 & 36.7 \\
\hline 5 & 0.203 & 0.075 & 0.569 & 38.3 \\
\hline 7.5 & 0.189 & 0.061 & 0.471 & 41.2 \\
\hline 10 & 0.162 & 0.056 & 0.445 & 35.5 \\
\hline
\end{tabular}


$\mu \mathrm{m}$. Diversification of the spacing on the samples described with the variation indicator $n(\lambda)$ and is approximate to the applied alternatives but it can be observed that the parameter increases for steel C70D together with the increase of cooling rate. Dependency of the average interlamellar spacing value $\left(\lambda_{a v}\right)$ from the cooling rate after deformation $(v)$ can be described with a good approximation with the use of power function [9]

Checking the cooling rate has a significant influence on the morphology of the pearlite in tested steels. The results of the conducted tests show that the optimal cooling rate should be included in the interval between $7.5 \div 10^{\circ} \mathrm{C} / \mathrm{s}$, due to the mean interlamellar spacing equal or smaller than $0.2 \mu \mathrm{m}$. In real conditions, where much bigger deformation rates are applied, there is a bigger number of defects in microstructure, so the required microstructure can be expected by smaller cooling rate.

Example microstructure of steel $\mathrm{C} 70 \mathrm{D}$ after rolling and quenching with average cooling rate $7.5^{\circ} \mathrm{C} / \mathrm{s}$ to a temperature about $600^{\circ} \mathrm{C}$ and next with furnace with a rate of $0.4^{\circ} \mathrm{C} / \mathrm{s}$ to $400^{\circ} \mathrm{C}$ is shown in (Fig. 4). Cooling with water spraying allows for the achievement of the proper super-cooling in order to decrease the temperature of pearlite transformation. Microstructure of steel consists of pearlite with a small amount of ferrite and the former austenite appearing in the area of grain boundaries (Fig. 4a,b). For the quantitative analysis of the pearlite areas and in particular the thickness of lamellae and the spacing between lamellae of cementite there were images registered on scanning microscope with magnification of up to $15000 \times$. After rolling in temperature $760^{\circ} \mathrm{C}$ the decomposition of pearlite due to a big overcooling, is observed in the microstructure of sample. (Fig. 4c,d)

A series of stereological parameters was marked in the form of average values (Table 3 ) and statistical distributions (Fig. 5). The biggest sensitivity to parameter changes of the rolling and cooling processes is visible in the average spacing between cementite lamellae $\lambda_{a v}$ (Fig. 5a) and average thick-

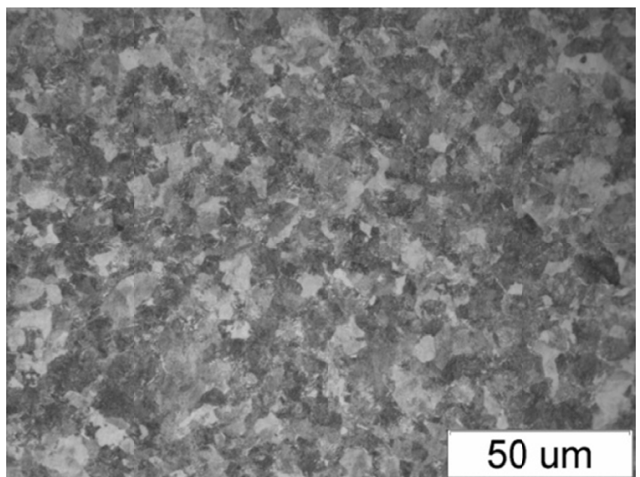

a) LM

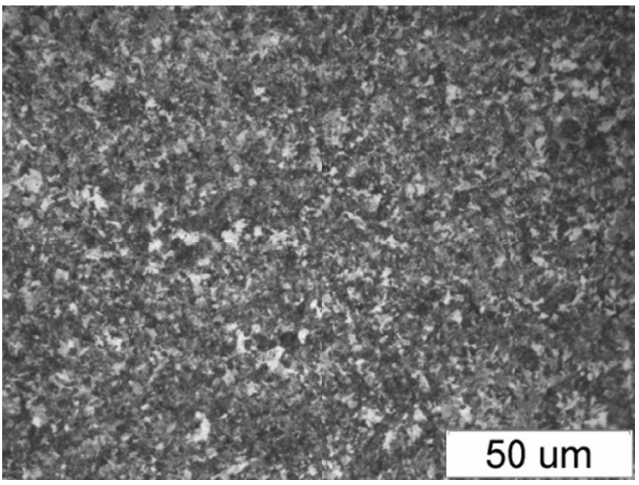

a) LM

\section{Rolling in $850^{\circ} \mathrm{C}$}

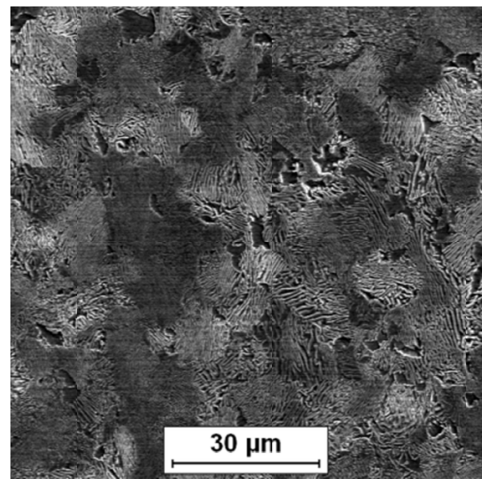

b) SEM

Rolling in $760^{\circ} \mathrm{C}$
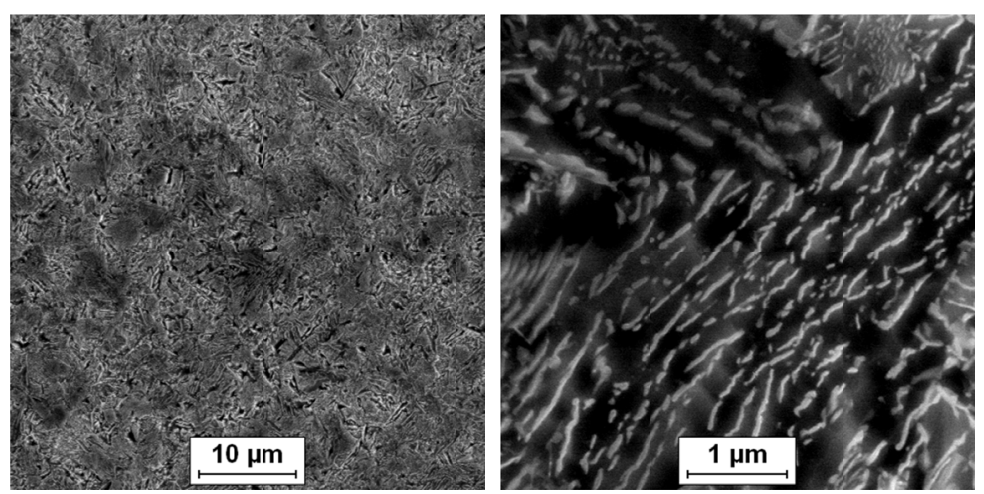

b) SEM

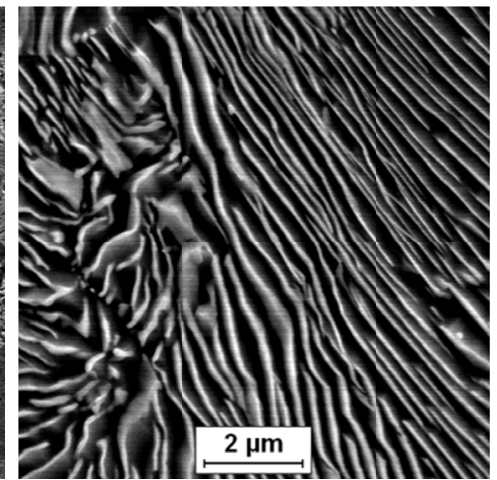

$2 \mu \mathrm{m}$

Fig. 4. Microstructure of C70D steel after rolling at temperature: $850^{\circ} \mathrm{C}$ (a) and 760 (b)

TABLE 2

Results of quantitative estimation of pearlite microstructure

\begin{tabular}{|c|c|c|c|c|}
\hline \hline Rolling temperature, $\left[{ }^{\circ} \mathbf{C}\right]$ & $\begin{array}{c}\text { Average distance of } \\
\text { lamellae } \lambda_{\boldsymbol{a v}}[\boldsymbol{\mu \mathrm { m }}]\end{array}$ & $\begin{array}{c}\text { Variation index } \\
\boldsymbol{n}(\boldsymbol{\lambda})[\boldsymbol{\%}]\end{array}$ & $\begin{array}{c}\text { Average thickness of } \\
\text { lamellae }\left(\boldsymbol{d}_{\boldsymbol{a v}}\right)[\boldsymbol{\mu m}]\end{array}$ & $\begin{array}{c}\text { Variation index } \\
\boldsymbol{n}(\boldsymbol{\lambda})[\boldsymbol{\%}]\end{array}$ \\
\hline 760 & 0.171 & 48.4 & 0.114 & 46.5 \\
\hline 800 & 0.198 & 34.5 & 0.082 & 33.0 \\
\hline 850 & 0.218 & 37.6 & 0.080 & 32.8 \\
\hline 900 & 0.331 & 35.3 & 0.130 & 35.1 \\
\hline
\end{tabular}




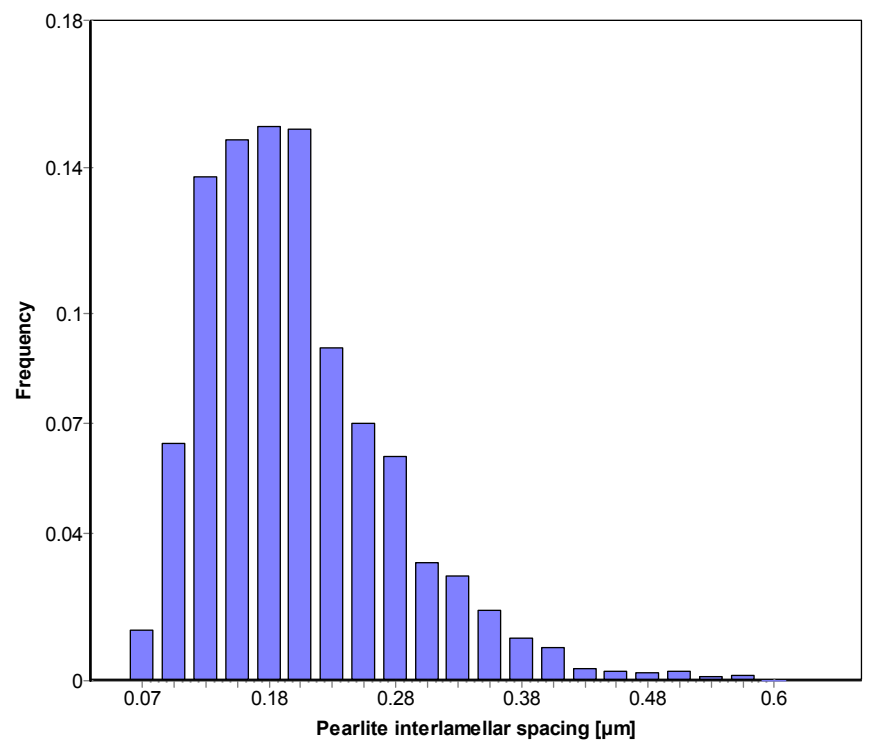

a)

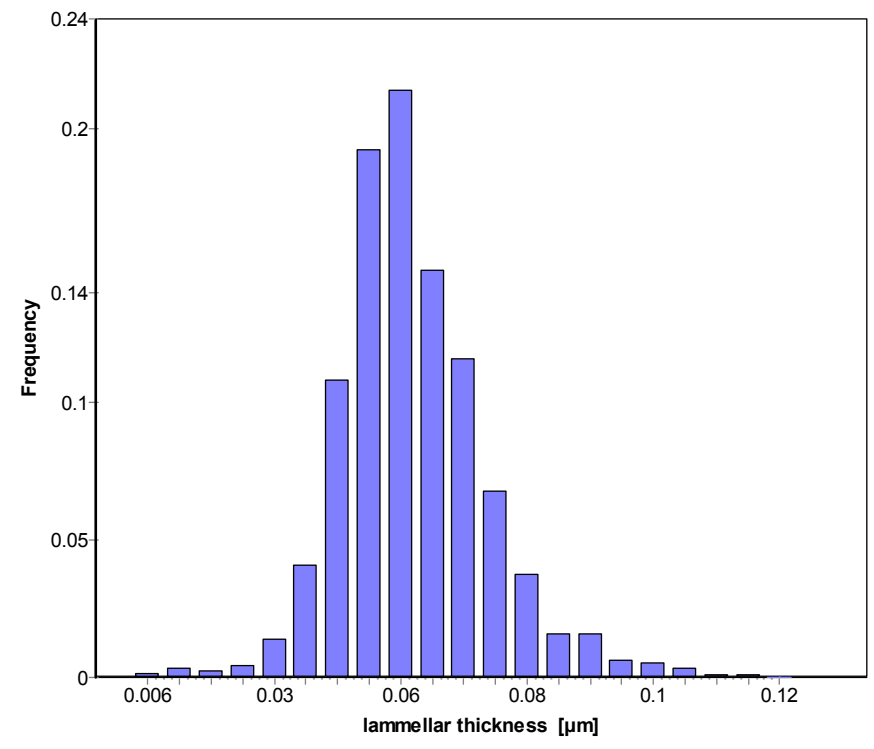

b)

Fig. 5. Distribution of pearlite interlamellar spacing (a) and lammellar thickness (b) in microstructure of steel sample after rolling at temperature $800^{\circ} \mathrm{C}$

ness of cementite lamellae $d_{a v}$ (Fig. 5b). It was found that the smallest spacing between lamellae of cementite is achieved for temperature of $760^{\circ} \mathrm{C}$, but inhomongeity is the highest (variation index $n(\lambda)=48 \%$ ). For these temperature of rolling the cementite lamellae also have the smallest thickness. The biggest spacing and thickness was found in a sample rolled in temperature of $920^{\circ} \mathrm{C}$.

Tests of mechanical properties of high-carbon steel C70D samples were conducted within the tasks after the process of rolling the microstructure of samples after physical simulation of heat-plastic treatment. Mechanical properties were tested on static materials testing machine ZWICK Z100 THW. Results of mechanical properties tests of samples prepared from steel C70D are presented in (Table 3). Together with the decrease of rolling temperature the mechanical properties increase. The biggest yield stress and ultimate tensile strength; is found in samples rolled in temperature of $760^{\circ} \mathrm{C}$. The value of elongation and contraction of area for applied parameters of rolling is similar, except temperature $760^{\circ} \mathrm{C}$. Optimal pearlite morphology with lamellar structure with rather small distance between lamellae was achieved after rolling in temperature of 800 and $850^{\circ} \mathrm{C}$. In lower temperature a defragmentation of pearlite and probable presence of bainite were observed. The confirmation

TABLE 3

Results of tensile test and Hardness (HV1) of the rolled samples in temperature of $760,800,850 \mathrm{I} 920^{\circ} \mathrm{C}$ with cooling, first in water shower and then with furnace

\begin{tabular}{|c|c|c|c|c|c|}
\hline \hline $\begin{array}{c}\text { Rolling temperature, } \\
{\left[{ }^{\circ} \mathrm{C}\right]}\end{array}$ & $\begin{array}{c}\mathrm{YS}_{0.2} \\
{[\mathrm{MPa}]}\end{array}$ & $\begin{array}{c}\text { UTS } \\
{[\mathrm{MPa}]}\end{array}$ & $\begin{array}{c}\mathrm{A} \\
{[\%]}\end{array}$ & $\begin{array}{c}\mathrm{Z} \\
{[\%]}\end{array}$ & HV1 \\
\hline 760 & 1020 & 1150 & 7,5 & 22,3 & 305 \\
\hline 800 & 705 & 1030 & 15,2 & 41,2 & 265 \\
\hline 850 & 695 & 1000 & 16,1 & 38,9 & 293 \\
\hline 920 & 615 & 925 & 18,0 & 41,5 & 262 \\
\hline
\end{tabular}

aspects of the achieved mechanical properties are the changes in microstructure and in particular the spacing between cementite lamellae in pearlite.

\section{Summary}

This paper presents the methodology of the quantitative description of pearlite in steel on which a new computer program PILS - Pearlite Inter-Lamellar Spacing is based. Suggested algorithms allow for an accurate measurement of interlamellar spacing and thickness of pearlite lamellae. Results can be presented in the form of diagrams or the variation indicators can be marked to characterise the heterogeneity of arrangement. Within verification the quantitative tests of microstructure in samples was conducted after simulation of physical heat-plastic treatment on deformation dilatometer with varied cooling rate for steel C70D. Realize research on the experimental rolling line in order to optimize the parameters of the process, especially the temperature of end of rolling and cooling rate after process aimed at achievement of microstructure of fine pearlite. It will enable the elimination of additional operations of heat treatment. Optimal pearlite morphology with lamellar structure with rather small distance between lamellae was achieved after rolling in temperature of 800 and $850^{\circ} \mathrm{C}$.In lower temperature a defragmentation of pearlite and probable presence of bainite were observed. Those results correlate with determined mechanical properties - samples with smallest inter-lamellar spacing have at the same time the highest resistance properties (Table 3). After rolling in temperature $760^{\circ} \mathrm{C}$ the highest strength was achieved, but it was found reduction of plasticity. Quantitative description in connection with parameters of the process can be elaborated by means of mathematical functions and applied in modelling the process $[10,11]$. Suggested methodology will be 
308

applied in quantitative assessment of the microstructure of steel after optimization of rolling process parameters for rolling wire rods taking into account especially the temperature of the end of rolling and cooling rate after the process in order to achieve fine pearlite with mean interlamellar spacing of below $0.2 \mu \mathrm{m}$. It was also stated that there is a possibility of the finish-rolling temperature decrease from currently applied $900-920^{\circ} \mathrm{C}$ to 800 $850^{\circ} \mathrm{C}$ without the loss of plasticity of samples. It will allow for elimination of additional operations of heat treatment.

\section{Acknowledgements}

This work was supported by Research Project of The National Centre for Research and Development of Poland No PBS/A5/32/2013

\section{REFERENCES}

[1] F. Grosman, D. Woźniak, Hutnik-Wiadomości Hutniczne 3, 97104 (2001).

[2] K. Laber, H. Dyja, B. Koczurkiewicz, Materials Testing 57 (4), 301-305 (2015).

[3] P. Kawulok, R. Kawulok, I. Schindler, S. Rusz, J. Kliber, P. Unucka, K.M. Čmiel, Metalurgija-Metallurgy 3, 299-302 (2014).

[4] G. Vander-Voort, The Interlamellar Spacing of Pearlite, http:// vacaero.com/information resources/metallography-with-george-vander-voort.

[5] G. Zhang, M. Enomoto, ISIJ International 49, 6, 921-927 (2009).

[6] V.T.L.Buono, B.M. Gonzalez, T.M. Lima, M.S.Andrade, Journal of Materials Science 32, 1005-1008 (1997).

[7] X Hu, P. Van Houtte, M. Liebeherr, A. Walentek, M. Seefeldt, H. Vandekinderen, Acta Mater. 54, 1029-1040 (2006).

[8] J. Szala, Application of computer image analysis method in the quantitative assessment of material structure, (2000), Silesian University of Technology, Gliwice.

[9] B. Koczurkiewicz, H. Dyja, G. Niewielski, METAL 2015: 24th International Conference on Metallurgy and Materials 699-703 (2015) Brno, Czech Republic

[10 D. Kuc, G. Niewielski, J. Cwajna, Materials Characterization 56, 318-324 (2006).

[11] D. Kuc, J. Gawąd, Arch. of Metall. Mater. 56 (2), 523-532 (2011). 